\title{
Economic Analysis of Law Review
}

\section{Uma abordagem de Law \& Economics para as Parcerias Público-Privadas no Brasil \\ A Law \& Economics Approach for Public-Private Partnerships in Brazil}

\author{
Rodrigo Nobre Fernandez ${ }^{1}$ \\ $P P G E-U F R G S$
}

Giácomo Balbinotto Neto ${ }^{3}$

$P P G E-U F R G S$

\author{
André Carraro ${ }^{2}$ \\ $P P G E-U F R G S$ \\ Rodrigo Vaz Silva ${ }^{4}$ \\ PPGE-UFRGS
}

\section{RESUMO}

A parceria público-privada (PPP) é espécie de contrato administrativo de concessão, que possui normas diferentes da concessão comum, podendo ser estabelecida na modalidade administrativa ou patrocinada. Neste trabalho fazse uma análise econômica do direito, no âmbito microeconômico, para as PPPs, como ferramenta utilizada pelo governo brasileiro para a execução de obras ou serviços em infraestrutura. Desta forma, expressaram-se os riscos causados pelos processos de assimetria de informação, além de problemas políticos gerados por grupos de interesses. Observou-se que o uso da PPP é uma boa alternativa em relação à concessão tradicional se a qualidade do serviço puder ser bem especificada no início do contrato, embora a qualidade da construção não possa, têm-se como exemplos, hospitais, presídios e aeroportos.

Palavras-chave: Parcerias-Público Privadas, Contratos Públicos, Análise Econômica do Direito.

JEL: L33, D86, K12.

\section{ABSTRACT}

The public-private partnership (PPP) is a species of administrative contract of concession which follows different rules of common concession, with the possibility of establishing it in an administrative or sponsored form. This study investigated, in a law and economics perspective, in a microeconomic view the PPP as a tool used by the Brazilian State for the execution of works or services in infrastructure. Thus, expressed the risks caused by the processes of asymmetric information and political problems generated by interest groups. It was observed that the use of privately managed primarily for services that require constant monitoring technology, to say, hospitals, prisons and airports can be good alternatives to the use of special concessions.

Keywords: Public-Private Partnerships, Public Contracts, Law \& Economics.

R: 11/9/13 A: 7/10/14 P: 30/3/15

\footnotetext{
${ }^{1}$ E-mail: rodrigo@rodrigofernandez.com.br.

${ }^{2}$ E-mail: andre.carraro@gmail.com.

${ }^{3}$ E-mail: giacomo.balbinotto@ufrgs.br.

${ }^{4}$ E-mail: rodrigovazsilva@gmail.com.
} 


\section{Introdução}

$s$ investimentos em infraestrutura são cruciais para o crescimento econômico de um país.

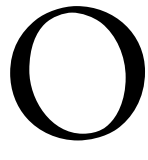
Energia elétrica, rodovias, portos, aeroportos, ferrovias, telecomunicações, habitação, escolas e hospitais, entre outros, são setores primordiais para a atração de novos investimentos produtivos e de capital humano. Apesar de importantes, estes investimentos possuem características que dificultam a sua realização. Eles, tipicamente envolvem, além de um grande volume de recurso financeiro, elevados custos iniciais, que em sua maior parte não são reutilizáveis em outros projetos econômicos (sunk costs). Essa característica, aliada ao longo período de tempo necessário para recuperar o capital investido, à incerteza sobre o comportamento de demanda futura, e aos elevados custos de operação e manutenção dos serviços oferecidos, fez com que esse tipo de investimento ficasse quase que exclusivamente sob a responsabilidade de governos.

De fato, governos são os atores econômicos, que até recentemente eram os únicos responsáveis por disponibilizarem os serviços básicos de infraestrutura para seus cidadãos. No entanto, por problemas orçamentários e de gerenciamento incorreto dos recursos públicos, houve uma crescente dificuldade para a provisão desse tipo de serviço público (Rioja, 2003). Como resposta a incapacidade dos governos, em continuar atendendo a crescente demanda por bens e serviços públicos, diversos países adotaram a alternativa da privatização. Usando uma variedade de modelos de privatização (Anderson e Hill, 1996), governos adotaram a privatização como modelo para buscar melhorias na eficiência e na retomada do investimento em infraestrutura. No entanto, a privatização, tida por alguns como o modelo teórico ótimo para a oferta de bens e serviços públicos, sofreu um rápido desgaste em relação à opinião pública, obrigando os governos a buscarem uma nova alternativa.

No continente europeu, essa procura teve início no Reino Unido, ainda na década de 1980, com a proposta da Iniciativa de Financiamento Privado (IFP). Essa modalidade definiu o setor público como responsável pela provisão de parte dos serviços ${ }^{6}$, utilizando a capacidade de financiamento do setor privado, dado que a disposição pública de investimentos estava reduzida devido aos limites impostos pelo tratado de Masstrich ${ }^{7}$. Com o decorrer do tempo, os projetos na modalidade de IFP foram ampliados, e no governo Tony Blair, no ano de 1996, esse tipo de relação jurídica passou a ser chamado de Parceria Público-Privada (PPP).

No âmbito nacional, em meados de 1995, entrou em vigor a lei das concessões ${ }^{8}$. Essa lei atende ao disposto no artigo 175 da Constituição Federal, que permite que o Estado conceda, de uma maneira geral, ao agente privado a execução de um serviço que possa ser prestado pelo ente público, mediante licitação, na modalidade de concorrência, que demonstre capacidade para seu desempenho, por sua conta e risco e por prazo determinado'. Por sua vez, as PPPs foram regulamentadas pela Lei no 11.079 de 30 de dezembro de 2004. Segundo as informações do Ministério do Plane-

\footnotetext{
5 "Private Finance Initiative" (Iniciativa de Financiamento Privado ou Investimento Financeiro Privado).

${ }^{6}$ Por exemplo, na construção de um hospital onde o agente governamental será o responsável por fornecer os profissionais capacitados (médicos enfermeiros etc.).

${ }^{7}$ Este tratado também é chamado de tratado da União Européia e foi assinado no dia 7 de Fevereiro de 1992 na cidade holandesa de Maastricht. A importância do mesmo está relacionada à integração já existente entre diversos países europeus se tornaria então uma unificação política. Assim, o nome Comunidade Européia é substituído pelo nome atual de União Européia.

${ }^{8}$ Lei n ${ }^{\circ} .8 .987 / 95$.
}

${ }^{9}$ Lei $n^{\circ} .8 .987 / 95$, artigo $2^{\circ}$, II.

EALR, V. 5, n² 2, p. 205-219, Jul-Dez, 2014 
jamento, Orçamento e Gestão ${ }^{10}$, no período de 2009-2010, o governo federal fechou contratos para alguns projetos usando este arranjo, dentre eles, o gerenciamento de um Data Center $^{l 1}$ da Caixa Econômica Federal, em conjunto com o Banco do Brasil, e o projeto pontal de irrigação no estado de Pernambuco e a Rede de Televisão Digital. No âmbito estadual o Observatório das Parcerias Público-Privadas lançou em 2011 o primeiro banco de dados de projetos estaduais de PPPS. Em seu relatório estão identificados 17 projetos, em sete estados brasileiros cujos contratos analisados somam um valor de 15 bilhões de reais. O setor mais representativo envolveu a construção ou reforma de estádios de futebol para a Copa do Mundo de 2014, seguido por saneamento básico, rodovias e sistema metroviário (Pereira e Prol, 2011).

Os exemplos mencionados evidenciam que a PPP está se tornando um importante mecanismo de provisão de bens e serviços públicos no Brasil. Seus defensores (entre eles, Hart, 2003; Bennet e Iossa, 2006; Martimont e Pouyet, 2008; Martimont e Iossa, 2009; Engel et al. 2008; Barros e Giralt, 2009; Nobrega, 2012) destacam três importantes argumentos que contribuiriam para que o modelo de PPP fornecesse uma infraestrutura mais eficiente. Um argumento comum na literatura é o fato de um projeto viabilizado por uma PPP, ao utilizar recursos privados para o seu financiamento, não estar limitado pela restrição orçamentária do governo. Esse fato permitira que governos pudessem ampliar a infraestrutura de um país, sem incorrer em maiores gastos públicos ou déficits em suas contas. Para um período caracterizado por conturbadas crises internacionais de déficits fiscais esse argumento tem se mostrado muito forte para incentivar governos a ampliar os contratos destas parcerias. Por outro lado, sendo o financiamento do investimento de origem privada, é razoável supor que o próprio mercado financeiro exigiria a aprovação de projetos eficientes. E, por fim, tendo o modelo de PPP, em sua origem, um processo competitivo via licitação, seria uma forma criativa de gerar competição de mercado dentro de um setor tipicamente monopolista como o de oferta de infraestrutura.

Apesar desses argumentos teóricos, algumas evidências empíricas demonstram que o produto da PPP pode ser incerto. Chong et al. (2006) analisam a PPP na França para o setor de água potável e concluem que a PPP resultou em um preço maior. Sob outra perspectiva, Guash (2004) relata casos de projetos abandonados ou em que o governo não conseguiu garantir o cumprimento do contrato. Ainda, Ribeiro (2013) descreve que no caso brasileiro um dos principais problemas da PPP é o falso cumprimento do contrato. Em resumo, empresas vencem a licitação com preços baixos, ganham o direito de serem monopolistas temporários na oferta da infraestrutura, mas logo em seguida a promessa de investimentos e da melhoria nos serviços não é cumprida. Trata-se não do descumprimento do contrato derivado do risco de ocorrência de evento não antecipado, mas de descumprimento racional e planejado do contrato. Em outras palavras, a forma como o contrato é desenhado pode gerar como resultado a escolha pelo seu descumprimento. Dessa forma, passa a ser de fundamental importância o estudo das relações contratuais e das possíveis contingências contratuais que possam gerar fracasso nas PPPs.

Neste sentido, o estudo da teoria dos contratos administrativos é um instrumento valioso que permite auxiliar os policymakers a realizarem o desenho de mecanismo correto que possibilite,

\footnotetext{
${ }^{10}$ Veja http://www.planejamento.gov.br/hotsites/ppp/conteudo/projetos/projetos.html

${ }^{11}$ É um local onde estão concentrados os equipamentos de processamento e armazenamento de dados de uma organização.
}

EALR, V. 5, nº 2, p. 205-219, Jul-Dez, 2014 
por exemplo, a obtenção do projeto mais eficiente de parceria público-privada. Ao fazer isso, o ente público atribuirá às condições necessárias para que o parceiro privado execute as ações apropriadas relacionadas a PPP.

Dentro deste contexto, o objetivo deste artigo está em realizar uma análise econômica do direito para as PPPs no Brasil. Para atingir-se tal meta, relacionam-se os aspectos relevantes destas concessões especiais no âmbito nacional e posteriormente aplica-se um modelo de contratos incompletos de Hart (2003) para entender-se como o governo realiza o desenho contratual.

Este estudo está estruturado em quatro partes, começando por esta introdução. Na seção dois, serão discutidas as especificidades da concessão especial como forma de arranjo em relação às concessões convencionais. Na seção seguinte será apresentado o problema de informação assimétrica, como um possível inconveniente nas relações contratuais de PPPs e em seguida mostra-se o modelo teórico de Hart (2003). Por fim, encerra-se com as considerações finais.

\section{Concessão Comum e PPPs: algumas considerações}

Inicialmente é necessário tecer considerações acerca das concessões comuns, tratadas na Lei 8.987, que exerce a função de lei geral das concessões ${ }^{12}$, e da chamada concessão especial (PPP) prevista na Lei 11.079 de 2004, que se divide nas espécies patrocinada e administrativa, apontando algumas diferenças importantes para o desenvolvimento deste trabalho.

Estes institutos materializam formas de o poder público transferir para o agente privado o poder-dever de prestar determinado serviço público, seja ele precedido de obra pública ou não. Em suma, destacam-se os elementos aderentes a cada tipo de concessão que são relevantes para a compreensão dos argumentos jurídico e econômicos pretendidos por este trabalho.

A concessão comum de serviço público, prevista na Lei 8.987, serve como paradigma para os atos administrativos que entregam a execução de determinado serviço para o particular ${ }^{13}$. A concessão é o instituto jurídico por meio do qual o Estado atribui o exercício de um serviço público a alguém que aceita prestá-lo, sob sua conta e risco e, em situação na qual o Estado possui controle maior sobre as cláusulas contratuais, mas com o respeito ao equilíbrio econômico-financeiro, obtendo remuneração da exploração da atividade (Bandeira de Mello, 2008).

As possibilidades de parcerias público-privada, tratadas pela legislação brasileira como hipóteses especiais de concessão, se destacam por suas modalidades "patrocinada" ou "administrativa", orientadas por normas próprias previstas na Lei 11.079 que se aplicam especialmente a tais modalidades (Bandeira de Mello, 2008). Essencialmente, a lei coloca, nos parágrafos $1^{\circ}$ e $2^{\circ}$ do artigo $2^{\circ}$, que na modalidade patrocinada o parceiro privado será remunerado tanto por tarifa cobrada dos usuários quanto por contraprestação pecuniária do parceiro público, enquanto que a concessão administrati-

\footnotetext{
${ }^{12} \mathrm{O}$ artigo $2^{\circ}$ da Lei 8.987 traz como conceito de concessão de serviço público a delegação da prestação do serviço público, sem entregar a titularidade da atuação (ao contrário da privatização). Já o artigo $2^{\circ}$ da Lei 11.079 , que trata das Parcerias Público-Privadas, coloca que as concessões especiais são formas de concessão, sendo que o artigo $3^{\circ}$ traz, dentre outras, a Lei 8.987 de forma subsidiária, no que não for contrária àquela.

${ }^{13}$ Quaisquer das formas de prestação de serviços públicos por particular pressupõem a entrega da execução do serviço para o particular, porém, a titularidade do serviço permanece com o Poder Público. A Lei 8.987 coloca nos incisos do artigo $2^{\circ}$ que tanto as concessões de serviço público quanto a permissão de serviço público envolvem a entrega da prestação do serviço.
}

EALR, V. 5, n² 2, p. 205-219, Jul-Dez, 2014 
va no qual o parceiro privado realiza sua atividade tendo a Administração Direta como destinatária direta ou indireta do serviço.

Dentro desse contexto, parte-se agora para algumas peculiaridades destes institutos. $\mathrm{O} \$ 3^{\circ}$ do artigo $2^{\circ}$ da Lei 11.079 centra-se no reconhecimento da natureza jurídica de uma PPP, pois determina que somente poderá ser considerada parceria público-privada a concessão de obras ou serviços públicos que envolver contraprestação pecuniária do parceiro público ao privado. Tal dispositivo traz elemento que especializa a natureza das PPPs em relação às concessões comuns, pois nas concessões regidas pela Lei 8.987, não poderá ocorrer pagamento, por parte do Estado, pelo serviço prestado pelo particular, derivando a remuneração do agente privado que presta o serviço público de tarifa paga pelo usuário ou outra forma de remuneração decorrente da exploração do serviço (Di Pietro, 2008).

A grande problemática das parcerias público-privadas em face das concessões comuns se dá no fato do compartilhamento dos riscos do contrato entre as partes parceiras nas PPPs. O artigo 25 da Lei 8.987 é claro ao determinar que incumbe à concessionária todos os prejuízos causados ao poder concedente, aos usuários e terceiros pela execução do serviço, sem que a fiscalização do órgão competente exclua ou atenue essa responsabilidade. O artigo $38, \$ 6^{\circ}$ da mesma lei também determina que em caso de caducidade do contrato, o poder concedente não será responsabilizado pelos encargos em geral com terceiros ou empregados ${ }^{14} \mathrm{da}$ concessionária.

Deste modo, a concessão comum, seja ela precedida de obra pública ou não, afasta, pelo menos a priori, do poder concedente, qualquer ônus gerado pelo não cumprimento adequado do contrato administrativo por parte da concessionária, blindando os cofres públicos de situações de risco econômico e financeiro ou de eventuais quebras no projeto.

Esse fato não ocorre nas PPPs, pois independente da espécie adotada, o poder público, notadamente por força do artigo $5^{\circ}$, inciso III, que prevê a necessidade de o contrato administrativo em questão trazer o compartilhamento dos riscos entre as partes, inclusive de potenciais responsabilizações relacionadas com caso fortuito, força maior, fato do príncipe e álea econômica extraordinária ${ }^{15}$. Tal previsão permite imputar à Administração inclusive as dívidas trabalhistas, previdenciárias, fiscais e comerciais de forma solidária, mesmo quando decorrentes explicitamente da má condução da parceria ou de qualquer ato ilícito do gestor privado.

Outro ponto de destaque para diferenciar as concessóes é o fato de a Lei 11.079 trazer a necessidade de criação de uma sociedade com propósito específico de gerir a parceria e o patrimônio atribuído a tal tarefa. Esta sociedade poderá ser gerida pelo parceiro privado, por força do art. $9^{\circ}$, nas PPPs, na hipótese de o poder público passar para o controle do gestor privado o patrimônio público colocado na parceria, apontando uma série de requisitos para que tal transferência ocorra no edital licitatório e no contrato ${ }^{16}$.

\footnotetext{
${ }^{14}$ Apesar da previsão do referido parágrafo encontrar eco no artigo 71 e parágrafos da Lei 8.666, que afasta expressamente a responsabilidade do poder concedente sobre dívidas trabalhistas, previdenciárias, fiscais e comerciais relativos à execução do contrato, o Tribunal Superior do Trabalho editou o Enunciado 331, no qual, contra legem, determina a responsabilização subsidiária do órgão da Administração Pública quando evidenciada conduta culposa no cumprimento da Lei 8.666.

${ }^{15}$ Corresponde a fatos, bem como: crises econômicas, desastres naturais e oscilações cambiais. Em tais situações, os prejuízos são compartilhados entre o concedente e o concessionário, dado o desequilíbrio da equação econômico-financeira.

${ }^{16}$ Os parágrafos do artigo $9^{\circ}$ da referida lei trazem a necessidade de previsão editalícia e contratual, a possibilidade de tal sociedade possuir capital aberto no mercado, além de dever atentar aos padrões de governança corporativa e adotar conEALR, V. 5, n² 2, p. 205-219, Jul-Dez, 2014 
Pode-se relatar que nesta forma de concessão especial a eficiência na alocação do risco é a combinação das qualidades de gestão pública com a habilidade e qualidade na prestação de serviços do setor privado. No entanto, deve haver uma combinação de responsabilidades, principalmente na concepção, construção e financiamento de determinado ativo, para que dessa forma seja justificada a formação de uma PPP.

De fato, é importante garantir que as PPPs serão voltadas para o aumento da eficiência na gestão de serviços públicos, em detrimento da gestão que apenas cria novas despesas. Para isto, a estrutura de contrato deve ser apropriada para garantir a transferência de riscos para o setor privado e também refletir de forma acurada as os custos do projeto. A Fig. 1 serve como um instrumento ilustrativo que permite visualizar os principais tipos de riscos associados à formação das PPPs, como segue:

Figura 1 - Caracterização dos riscos associados à formação de PPPs

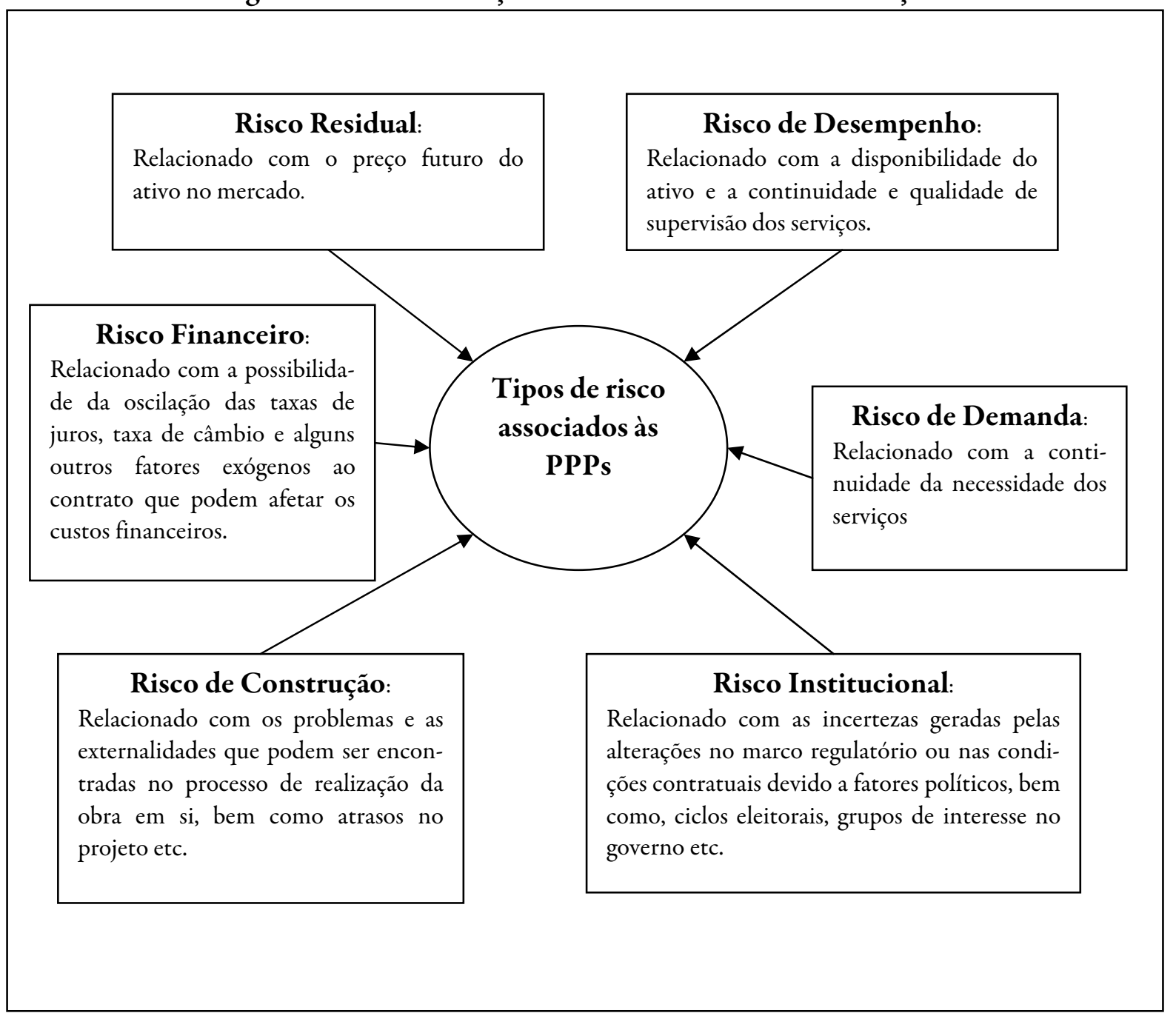

Fonte: Elaborado pelo autor com base em IMF (2004), Montoro Filho (2004) e Menezes (2005).

tabilidade e demonstrações financeiras padronizadas, conforme regulamento, trazendo ainda o impedimento de a Administração Pública ser titular da maioria do capital votante das sociedades participantes, o que denota a intenção do legislador de fazer com que a gestão de tal sociedade seja privada.

EALR, V. 5, n² 2, p. 205-219, Jul-Dez, 2014 
Sumariamente, esses grupos de riscos definem as principais preocupações relacionadas à formação destas parcerias. Loyola apud Fernández (2006) destaca o risco financeiro, tendo em vista que o setor público deve estabelecer garantias, sendo uma delas a obrigação contratual para aquisição futura dos serviços providos pela empresa privada.

Outro aspecto importante a ser considerado é o risco político. O fato de a PPP ser um contrato incompleto, dado que os agentes não conseguem prever todas as possíveis contingências que podem suceder ao decorrer do tempo, pode gerar resultados ineficientes. Guasch (2004) analisa o caso de governos politicamente fracos, os quais toleram informações imprecisas sobre as atividades das firmas envolvidas no momento da negociação de uma PPP, que podem resultar em propostas irrealistas, as quais deverão ser revistas logo após o início da operação pela concessionária.

A suposição de Guasch (2004) é interessante, mas a tolerância, por parte do agente governamental, em aceitar informações imprecisas por parte $\mathrm{da}(\mathrm{s})$ empresa(s) concorrente(s) pode estar relacionada ao $l o b b y^{17}$ ou a possíveis incentivos recebidos dos agentes privados. Mitchell e Simmons (2003) entendem que os agentes privados podem formar grupos para dominar ou deter uma grande fatia em determinados mercados.

Nesse sentido, o governo poderá favorecer determinados grupos, por meio de imposições políticas que beneficiem algumas empresas de determinada atividade. $\mathrm{O}$ agente público pode buscar a corrupção como uma forma substituta ou até mesmo complementar às estratégias de looby ${ }^{18}$ político, para privilegiar os grupos de interesse na obtenção dos objetivos desejados (Tullock, 1967; Posner, 1975; Bhagwati, 1982). Os políticos também podem optar pelo uso do rent-seeking visando o processo de futura reeleição ou o favorecimento de atuais negócios privados. Esses autores definem o rentseeking baseando-se no conceito de renda (rents), isto é, o ganho que excede todos os custos relevantes e se aproxima do lucro de monopólio. Essa atividade não é necessariamente ilegal, mas é economicamente improdutiva e ineficiente.

Um dos fatores primordiais para o sucesso das parcerias é o comprometimento político e a boa governança. A incerteza sobre o comportamento do setor público origina o risco político, que não é apropriado para a tomada de decisões de longo prazo. Dessa forma, é importante que sejam estabelecidos claros canais de responsabilidade do agente público e do agente privado na formação das PPPs. A corrupção governamental pode ser considerada como um sério obstáculo ao êxito das PPPs, da mesma maneira que impediu a privatização bem-sucedida (Lora e Panizza, 2003).

Por fim, Peci e Sobral (2007) relatam que o processo de transferência de risco para o setor privado é muito mais restrito, pois os riscos de financiamento e garantias são assumidos pelo setor público, o que de fato não acontece ao realizar-se uma concessão convencional, em que o risco do empreendimento é passado para a empresa responsável pelo projeto. Além disso, há outras garantias que podem ser obtidas por organismos internacionais ou por seguradoras. A partir daqui observa-se como os problemas relacionados à informação podem dificultar ou incidir em risco dentro dos processos contratuais, que é um elemento chave para a formação de uma PPP.

\footnotetext{
${ }^{17}$ Tentativa de influenciar alguma decisão de política pública em benefício de algum grupo de interesse.

${ }^{18}$ Atividades de um grupo organizado para interferir em decisões políticas.

EALR, V. 5, nº 2, p. 205-219, Jul-Dez, 2014
} 


\section{Assimetria de informação no âmbito das PPPs}

Um dos problemas relacionados aos riscos na elaboração de contratos é a diferença de informação entre os agentes. Se umas das partes envolvidas no contrato possui alguma informação privilegiada ou maior nível de instrução sobre os processos de uma determinada atividade poderá utilizar essa diferença informacional para se beneficiar. $\mathrm{O}$ fato de algum dos entes envolvidos (as firmas e os governos) na parceria ter acesso exclusivo a determinada informação caracteriza um problema de informação assimétrica, que de modo geral, envolve duas dimensões: uma exógena (seleção adversa) e outra endógena (risco moral). Hart (2003) reforça estas suposições destacando que a literatura econômica em relação à teoria da firma toma uma perspectiva de contratos incompletos, no qual as ineficiências aumentam devido à dificuldade de se prever o futuro. A origem dessas imperfeiçôes dá lugar ao problema de seleção adversa e risco moral.

De acordo com Pires e Giambiagi (2000) a ocorrência do fenômeno da seleção adversa se dá porque o governo, no caso das PPPs, não possui a mesma quantidade de informações que a empresa, a respeito da eficiência dos processos da mesma. O risco moral ocorre já que somente a firma possui o conhecimento dos resultados de determinados movimentos intrinsecamente endógenos, bem como, custos e medidas administrativas, o que permite a ela modificar estes valores para obter alguma vantagem quando os contratos são definidos.

Visando entender como o problema de seleção adversa pode promover um risco para o agente governamental, utiliza-se a intuição dada por Akerlof (1970). Em seu texto clássico, o autor infere que os indivíduos irão buscar informações estatísticas sobre a qualidade do bem para efetuar a sua compra. No mercado de carros usados, há veículos de boa qualidade e os "limões ${ }^{19}$ ". Desta forma, o proprietário de um limão, pode aproveitar que o retorno dos bens de boa qualidade recaia para o grupo todo. Ou seja, o preço a ser pago no mercado tenderá a ser o médio e o consumidor final terá problemas ao selecionar seu veículo. Analogamente, nos processos de escolha do empresariado para o estabelecimento dos contratos de PPPs, o último pode utilizar o que se chama de maquiagem para reduzir custos e ganhar o processo de concorrência ${ }^{20}$. Se à primeira vista esse resultado demonstra eficiência, percebe-se logo a seguir que a estratégia de redução artificial dos custos gera a necessidade de uma renegociação de contrato (risco contratual), visto que os custos estimados não estão adequados à realidade financeira da obra.

Nesta perspectiva, Nóbrega (2012) destaca o que a literatura denomina "jogo da partilha", que se caracteriza pela apresentação de propostas feitas pelas empresas com base em planilhas de custos que num primeiro momento aparentam ser vantajosas, mas que não estão de acordo com a realidade econômica. Isto é, a firma consegue este resultado omitindo ou subestimando os custos dos insumos que seriam utilizados na execução do projeto. No contexto nacional, com base num argumento permissivo da lei $n^{\circ} 8.666$ as empresas alegam que não poderiam executar o contrato com base no equilíbrio financeiro econômico e solicitam a atualização do mesmo.

Por outro lado, deve-se ressaltar que qualquer prática que vise ludibriar o Poder Público, incluindo a realização de maquiagem em dados fornecidos, poderá caracterizar um ou mais crimes cometidos por particular contra a Administração Pública, previstos no Código Penal e, além dos crimes

\footnotetext{
${ }^{19}$ Os "limões" relatados pelo autor seriam os “abacaxis", ou seja, carros de má qualidade que recebem um tipo de maquiagem para serem negociados como sendo de melhor qualidade.

${ }^{20}$ A seleção da firma vencedora pode ser feita através de um processo licitatório.

EALR, V. 5, n² 2, p. 205-219, Jul-Dez, 2014
} 
previstos na Lei de Licitações, sem prejuízo de eventual responsabilização por improbidade administrativa, conforme a Lei 8.429/92. A apresentação intencional de dados falsos pode ser enquadrada, dependendo da forma dos atos, o crime de frustrar ou fraudar, mediante qualquer expediente, o caráter competitivo do procedimento licitatório, com o intuito de obter para si ou para outrem vantagem decorrente da adjudicação do objeto da licitação ${ }^{21}$.

Seguindo nesta linha, pode-se resgatar o conceito apresentado por Spence (1973) de que os agentes econômicos sinalizam por meio da demonstração do seu desempenho. Dentro desse contexto, o Estado pode tentar minimizar o problema de seleção adversa e de risco moral, buscando entender quais são os sinais fornecidos pelas empresas candidatas à formação da parceria. Uma boa forma de entender como o ente público pode desenvolver esta tarefa é tomar por base o portfólio ${ }^{22} \mathrm{da}$ empresa. A análise dos serviços e atividades previamente prestados pela empresa pode fornecer informações interessantes sobre o comprometimento e qualidade da entidade. Ou seja, os agentes envolvidos neste arranjo incorrerão com que Spence (1973) define como custos de sinalização.

Conforme a abordagem demonstrada, tais gastos estariam inseridos nos custos de oportunidade dos setores público e privado ao firmarem assinatura do contrato. Mesmo que a sinalização seja importante para redução da assimetria de informação, esses valores pagos com este processo poderiam estar implícitos dentro dos mercados competitivos. Isto é, a especificidade de grandes projetos, como o caso das PPPs, conduz ao surgimento do hold up problem (problema do refém), possibilitando que uma parceira explore a fragilidade da outra em uma possível futura negociação. De acordo com Nóbrega (2012), isso ocorre claramente em contratos de infraestrutura, porque há custos irrecuperáveis e os investimentos são muitos específicos, ou seja, não há alternativas para eles.

Neste sentido, os contratos estabelecidos para a formação das PPPs se encaixam na abordagem de Holmstrom e Milgrom (1991) em que os autores analisam o problema do principal e do agente. O governo é considerado o principal, dado que é o responsável por contratar, já a empresa privada verifica se a proposta de contrato é relevante para sua estrutura de trabalho, sendo tratada como o agente. Cabe ao principal fornecer incentivos para que o agente assine o contrato da forma estabelecida por ele. Em contrapartida, o agente deve aceitar o contrato caso avalie que a proposta recebida é melhor que a alternativa de mercado e, se ela supre seu nível reserva de utilidade. Caso contrário, o agente não assinará o contrato. $\mathrm{O}$ desenho contratual é uma ferramenta proveniente da teoria de contratos que usa mecanismos para desenvolver estruturas de contratos que incorporem assimetria de informação e que permite avaliar o possível comportamento dos agentes dado a existência de eventuais problemas não previstos.

\subsection{Modelo contratual}

Uma das características chave da relação contratual em uma PPP é a dificuldade de desenhar um contrato que preveja os incentivos necessários, para que a empresa ganhadora da licitação tenha no momento seguinte o comportamento desejado pelo governo. $\mathrm{O}$ aspecto primordial para o entendimento desta questão está relacionado com a escolha de quem deterá a propriedade do ativo no final do contrato. Essa escolha pode determinar como ocorrerão os incentivos que irão determinar a qua-

\footnotetext{
${ }^{21}$ Artigo 90 da Lei 8.666.

${ }^{22}$ Portfólio é o conjunto de ações ou ativos pertencentes a uma firma. Imagina-se que os clientes podem ser considerados como componentes do portfólio da empresa devido a sua importância par ao negócio.

EALR, V. 5, no 2, p. 205-219, Jul-Dez, 2014 
lidade do projeto. Com o intuito de abordar o caso brasileiro, segue-se o modelo proposto por Hart (2003).

Supõe-se que o governo deseja construir um ativo e possui duas alternativas para fazê-lo: contratar um terceiro para construção e operação do projeto, o que por hipótese caracteriza-se uma PPP, ou contratar duas empresas diferentes, o que se define por contrato tradicional. Assume-se que o contrato é incompleto no sentido de que o construtor e o operador podem modificar a natureza da construção ou dos serviços que serão prestados sem violar os termos especificados contratualmente.

As empresas responsáveis pelo projeto podem realizar dois tipos de investimento: $i$ é o investimento produtivo que torna o empreendimento mais atrativo e de fácil funcionamento e " $e$ " é o investimento não produtivo que reduz os custos totais, mas também diminui a qualidade do projeto. Por exemplo, no processo de construção de uma prisão ou de um hospital, um melhor desenho do projeto, das disposições das salas, andares etc, facilitariam a operação desses empreendimentos. Em relação a um investimento não produtivo, imagine a compra de equipamentos mais baratos, mas que o uso dos mesmos seja mais complicado. Certamente isso reduz o custo, mas aumenta o tempo de execução das tarefas relacionadas ao uso desses equipamentos, ocasionando uma redução da qualidade.

O horizonte (timing) contratual é divido em três partes e ocorre da seguinte forma: A construção é realizada entre os períodos zero e um e os serviços são operados nas datas um e dois.

$$
\begin{gathered}
B=B_{0}+B(i)-b(e) \\
C=C_{0}-\gamma(i)-c(e) \\
D=i+e
\end{gathered}
$$

Onde: $B, b, \gamma, c>0, B^{\prime}>0, b^{\prime}>0, \gamma^{\prime}>0, c^{\prime}>0$ e $B^{\prime \prime}<0, b^{\prime \prime}>0, \gamma^{\prime \prime}<0, c^{\prime \prime}<0$.

A equação (1) denotada por B representa o benefício para a sociedade (medido em unidades monetárias) da execução do projeto após a sua construção. A mesma possui um componente fixo $B_{0}$ que independe da variação dos investimentos $i \mathrm{e} e$. Os componentes variáveis desta equação são representados por $B(i)$ e $b(e)$, sendo que o primeiro é uma função côncava de $i$, isto é, cresce em relação a este parâmetro a taxas decrescentes e $b(e)$ representa o custo específico de realizar-se o investimento não produtivo.

Em seguida a equação (2) representa os custos para o operador. O componente $C_{0}$ implica em um custo fixo que independe do nível de investimento. Os demais componentes são, $\gamma(i)$ e $c(e)$. Ambas as funções são côncavas em relação aos parâmetros, o que significa que as mesmas crescem a taxas decrescentes conforme se incrementa $i$ e $e$. Por fim, a equação (3) representa o investimento do construtor que por simplicidade depende linearmente de $i$ e $e$. Em resumo, o investimento produtivo $i$ aumenta o benefício para a sociedade e reduz o custo de operação e construção. Já um investimento não produtivo, reduz os custos, mas também afeta negativamente o benefício social.

Primeiramente, mostrar-se-á o caso em que os contratos são completos no sentido que o governo consegue induzir as empresas a realizarem a escolha $i$ e $e$ que maximize o seu benefício líquido (B-C-D). Em outras palavras o ente público consegue contratar as variáveis de investimento $i$ e $e$, como segue: 


$$
\operatorname{Max} \underset{i, e}{W}=B_{0}+B(i)-b(e)-C_{0}+\gamma(i)+c(e)-i-e
$$

As condições de primeira ordem são dadas por:

$$
\begin{aligned}
& B^{\prime}\left(i^{*}\right)+\gamma^{\prime}\left(i^{*}\right)=1 \\
& c^{\prime}\left(e^{*}\right)-b^{\prime}\left(e^{*}\right)=1
\end{aligned}
$$

As equações (5) e (6) representam que o benefício marginal de realizar o investimento produtivo é exatamente igual ao custo marginal de realizá-lo. Intuitivamente pode-se pensar na solução de canto $\mathrm{e}^{*}=0$. A mesma representa que o investimento não produtivo $e$ gera uma solução que pode ser considerada como socialmente não produtiva. Assim tem-se que a equação (6) assume a seguinte forma:

$$
c^{\prime}(0)-b^{\prime}(0) \leq 1
$$

Esta equação relata que a perda de benefício social ao realizar $\mathrm{e}^{*}=0$ é superior à redução de custo para este nível de investimento não produtivo. O próximo passo é avaliar quais são os resultados ótimos para o caso de contratos incompletos, em que os investimentos $i$ e $e$ são não contratáveis.

Primeiramente começa-se pelo caso de contratos separados. Nessa modalidade, o governo contrata a empresa construtora no período zero e faz um processo licitatório no período um para contratar a empresa responsável pela operação do empreendimento. Por suposição, este processo é competitivo, ou seja, a empresa vencedora obterá lucro econômico zero. Nesse caso o governo pagará ao operador um preço exatamente igual ao custo de operação $C=C_{0}-\gamma(\hat{i})-c(\hat{e})$, onde $\hat{e}$ e $\hat{i}$ são as variáveis de escolha de equilíbrio do construtor. Como as funções $B$ e $C$ são não verificáveis, o ente público está restrito aos contratos que especifiquem o pagamento $P_{0}$ ao construtor, de modo que o problema desta empresa é:

$$
\operatorname{Max}_{i, e} P_{0}-D=P_{0}-i-e
$$

Note que a solução desse problema é bastante simples com $\hat{e}=\hat{i}=0$. Com estes parâmetros o construtor realizará a obra do modo mais barato possível, isto é, ele não internalizará os possíveis ganhos advindos de uma externalidade entre os processos de produção (construção e operação). Desta forma o payofflíquido do governo é $B-C-P_{0}=B-C-D$ avaliado em $\hat{e}$ e $\hat{i}$.

Por outro lado, a estrutura de contrato de PPP se dá da seguinte forma: O governo oferece um contrato na data zero e especifica a qualidade básica do serviço a ser provido entre as datas um e dois e paga um preço $P$. Dessa forma, o construtor internaliza o custo da provisão do serviço ou subcontrata alguém. No último caso, supõe-se que haja novamente competição e o construtor pagará ao operador um preço igual ao custo $C=C_{0}-\gamma(\tilde{i})-c(\tilde{e})$. Tem-se que na data zero o construtor escolhe $i$ e $e$ visando solucionar:

$$
\operatorname{Max}_{\tilde{i}, \tilde{e}} P-C-i-e=P-C_{0}-\gamma(\tilde{i})-c(\tilde{e})-\tilde{i}-\tilde{e}
$$

E então se tem que:

EALR, V. 5, nº 2, p. 205-219, Jul-Dez, 2014 


$$
\begin{aligned}
& \gamma^{\prime}(\tilde{i})=1(8) \\
& c^{\prime}(\tilde{e})=1(9)
\end{aligned}
$$

Novamente as equações (8) e (9) relatam que o custo marginal de executar um investimento produtivo é igual o benefício marginal de efetuá-lo. Se a oferta dos construtores for competitiva, então $P=C+i+e$ e, o pagamento líquido do governo será $B-P=B-C-i-e$ ambos avaliados em $\tilde{i}$ e $\tilde{e}$. Neste contrato, o construtor não internaliza $B$, contudo internaliza $C$ e, assim executa um investimento mais produtivo. Há um claro dilema entre as duas situações. Quando se tem contratos separados, " $i$ " e " $e$ " são iguais a zero. Ou seja, o construtor faz um investimento produtivo muito pequeno, mas realiza o montante certo do investimento não produtivo. No caso da PPP há algum investimento produtivo, mas também ocorre um investimento improdutivo mais elevado que o nível ótimo.

O modelo produz algumas considerações interessantes. A prestação de serviço convencional é a melhor forma de contratação pública se a qualidade da construção puder ser bem especificada enquanto que a qualidade do serviço não puder ser observada. Sob essas condições o subinvestimento em $i$ não é um problema tão grave. Em contraste, a PPP é uma boa forma de contratação se há boas medidas de desempenho que possam ser utilizadas para premiar o penalizar o prestador de serviços, enquanto que a qualidade da construção ou do desenho do empreendimento não pode ser medida acuradamente. No caso das PPPs o sobreinvestimento em $e$ pode ser internalizado pelos agentes econômicos.

Nesse sentido, a construção de um complexo prisional e hospitalar podem não ser tarefas fáceis, mas com o auxílio de bons indicadores de qualidade a prestação de serviços hospitalares e indicadores de desempenho quanto à segurança do presídio e a ressocialização de presidiários podem ser instrumentos que favoreçam o uso da PPP. Uma situação semelhante pode ser vista em relação aos aeroportos. Um exemplo oposto seriam os empreendimentos relacionados a tecnologia de informação, como por exemplo, a construção de um centro de processamento de dados, onde a qualidade da construção é relativamente simples de ser verificada, no entanto, checar a qualidade/efetividade de prestação dos serviços não é uma tarefa simples.

No âmbito nacional, de acordo com o que se observa nas Leis 8.666/93 e 11.074/04 há uma dificuldade em adicionarem-se variáveis como custo de transação e assimetria informacional, no modelo proposto os níveis de investimento $i \mathrm{e} e$. Alternativamente a mudança da estrutura de propriedade, isto é, permitir que a firma administre o projeto após a sua conclusão, pode gerar incentivos positivos que aumentem o investimento $i$ e gerariam uma maior qualidade na prestação dos serviços públicos.

Além disso, o governo pode (e deve) ser mais rigoroso no controle e na exigência de transparência e de responsabilidade de seu parceiro. Estas ferramentas legais de fiscalização estão à disposição do Poder Público e permitem um melhor controle na seleção do parceiro privado, bem como da execução da parceria em si. Embora a fiscalização gere mais gastos para o Governo, a contrapartida em termos de custo de oportunidade pode fazer com que esta conta seja positiva.

\section{Considerações finais}

Este trabalho teve por objetivo realizar uma análise econômica do direito, no âmbito microeconômico, para o uso das concessões especiais, como ferramenta utilizada pelo governo brasileiro 216

EALR, V. 5, n² 2, p. 205-219, Jul-Dez, 2014 
para a execução de obras de infraestrutura. Por meio dessas, o ente público pode aumentar os investimentos em serviços para a sociedade, reduzir os gargalos da sua economia, sem comprometer a sua contabilidade. Cabe destacar, que as concessões parecem ser um avanço contratual em comparação com a experiência de privatizações por construir um arranjo contratual, no qual o governo possa continuar sendo o gestor da política pública contando com a prestação do serviço do setor privado.

Neste sentido, a questão do compartilhamento do risco é primordial e diferencia os contratos de concessão comum e PPP. A última expõe o governo aos riscos que são somente de responsabilidade do agente privado na concessão comum o que pode parecer num primeiro momento perigoso e ineficiente. Entretanto, o uso da gestão privada, para serviços que a qualidade de prestação pode ser contratualmente bem especificada, como, hospitais, presídios e aeroportos, podem tornar-se boas alternativas para emprego das PPPs. A possibilidade de melhorias na gestão desses serviços por meio de uma administração mais eficiente e moderna vislumbra ganhos para a sociedade.

No entanto, o uso de modelos microeconômicos destaca que os problemas relacionados à assimetria de informação podem influenciar no processo de tomada de decisão. Entre outros tantos problemas de informação existentes, a qualidade da prestação do serviço também é um fator difícil de ser monitorado pelo ente governamental. Mesmo que o parceiro privado apresente um bom portfólio, pode e deve ser difícil para o governo monitorar o esforço e a qualidade do projeto, caindo assim no problema do risco moral. Ademais, em um ambiente de contratos incompletos a análise inerente ao modelo de Hart (2003) conclui que a PPP é uma boa alternativa em relação à concessão tradicional se a qualidade do serviço puder ser bem especificada no início do contrato, enquanto que a qualidade da construção não pode.

Por outro lado, os gestores públicos podem agir em prol de pequenos grupos, através do processo de lobby (rent-seeking), ou visando adquirir ganhos (corrupção), barrando ou novamente privilegiando determinados grupos. $\mathrm{O}$ aumento do nível de gastos ou a possibilidade de renegociação dos contratos de concessões podem ser incentivos válidos para que os políticos, os quais estão no poder, utilizem estes mecanismos como alavanca para futuras campanhas políticas buscando sua reeleição.

Em suma, tomou-se conhecimento que as concessões exigem esforços para evitar o comportamento oportunista, tanto das empresas concorrentes, quanto por parte do governo. Apesar da existência de riscos contratuais, no caso da PPP, essa deve ser rígida na revisão de contratos para evitar o seu abuso indevido. Nesse sentido, uma possível nova contribuição seria avaliar seu impacto temporal e a influência dos ciclos eleitorais nessa nova forma de contratação pública. Além disso, analisar como a assimetria de informação pode influenciar a decisão dos agentes ou incentivar a grupos de interesse e corrupção.

\section{Referências bibliográficas}

Akerlof, G. A. (1970) The Market For Lemons: Quality, Uncertainty and the Market Mechanism. Quarterly Journal of Economics. 84(3), 488-500.

Akitoby, B., Hemming, R. \& Schwartz, G. (2006). Public Investment and Public-Private Partnership. International Monetary Fund Economic Issue.

Anderson, T. \& Hill, P. (1996). The Privatization Process: A Worldwide Perspective. Lanham, MD: Rowman \& Littlefield Publishers.

Bandeira de Mello, C. A. (2008). Curso de Direito Administrativo. 25. ed. São Paulo: Malheiros. 
Barros, P. P. \& Giralt, X. M. (2009). Contractual Design and PPPs for hospitals: lessons for the Portuguese model. European Journal of Health Economics. 10, 437-453.

Bennett, J. \& Iossa, E. (2006). Building and managing facilities for public services. Journal of Public Economics, 90(10-11), 2143-2160.

Bhagwatti, J. N. (1982). Directly Unproductive Profit Seeking Activities. Journal of Political Economy. 90, 988-1022.

Chong, E., Huet, F., Saussier, S. \& Steiner, F. (2006). Public-Private Partnerships and Prices: Evidence from Water Distribution in France. Review of Industrial Organization, 29, 149-169.

Di Pietro, M. S. Z. (2008). Direito Administrativo. 21. ed. São Paulo: Atlas.

Engel, E., Fisher, R. \& Galetovic, A. (2009). Soft budgets and renegotiations in public-private partnerships. Working Papper 15300. National Bureau of Economic Research.

Fernandez, S. E. V. (2006). Parcerias Público Privadas (PPP) no Setor Rodoviário: Um estudo da concordância entre o objeto do contrato e a forma jurídica dos contratos no Brasil. Dissertação (Mestrado em Controladoria e Contabilidade) - Universidade de São Paulo - USP.

Guasch, J. L. (2004). Granting and Renegotiating Infrastructure Concessions: Doing it Right. WBI Development Studies. Washington: The World Bank.

Giambiagi, F. et al. (2004). Economia Brasileira Contemporânea. Rio de Janeiro: Campus.

Hart, O. (2003). Incomplete contracts and public ownership: remarks and an application to publicprivate partnerships. Economic Journal. 119(488), 69-76.

Holmstrom, B. \& Milgrom, P. (1991). Multitask Principal-Agent Analyses: Incentive Contracts, Asset Ownership, and Job Design. Journal of Law, Economics and Organization.

IMF. (2004). Public-Private Partnership. International Monetary Fund Economic Issue.

Lora, E. \& Panizza, U. (2003). The Future of Structural Reforms. Journal of Democracy.

Martimont, D. \& Iossa E. (2008). The Simple Micro-Economics of Public-Private Partnerships. Department of Economics and Finance Working Paper n. 09-03. Brunel University.

Martimont, D. \& Pouyet, J. (2008). To Build or Not to Build: Normative and Positive Theories of, Private-Public Partnerships. International Journal of Industrial Organization.

Menezes, A. M. F. (2005). Desenvolvimento Econômico Sustentável e seu financiamento: Uma análise da Parceria Público Privada. In: I Encontro de Economia Baiana, Salvador.

Mitchell, W. \& Simmons, R. (2003). Para Além da Política: Mercados, Bem-Estar e o Fracasso da Burocracia. Top Books.

Montoro Filho, A. F. (2004). Parceria Público Privado: considerações de um economista. Boletim Informações FIPE.

Nóbrega, M. (2012). Análise Econômica do Direito Administrativo. In: Timm, L. B. (Org.). Direito e Economia no Brasil. 1ª. ed. São Paulo: Atlas.

Peci, A. \& Sobral, F. A. (2007). Parcerias Público-Privadas: uma análise comparativa das experiências britânica e brasileira. Cadernos EBAPE.BR (FGV).

Pereira, B. \& Prol, F. M. (2011). Relatório sobres as PPPs estaduais. Disponível em $<$ http://www.pppbrasil.com.br/portal/content/relat\%C3\%B3rio-sobre-ppps-estaduais $>$. Acesso em: 10 de ago. 2013.

Pires, J.C. L. \& Giambiagi, F. (2000). Retorno dos Novos Investimentos Privados em Contextos de Incerteza: Uma Proposta de Mudança do Mecanismo de Concessão de Rodovias no Brasil. Rio de Janeiro. BNDES (Texto Para Discussão n. 81).

EALR, V. 5, nº 2, p. 205-219, Jul-Dez, 2014 
Posner, R. A. (1975). The Social Cost of Monopoly and Regulation. Journal of Political Economy. Ribeiro, M. P. (2013). Concessões e PPPs: o que temos a aprender com o falso cumprimento dos contratos? Disponível em: $<$ http://www.pppbrasil.com.br/portal/content/artigoconcess\%C3\%B5es-e-ppps-o-que-temos-aprender-com-o-falso-cumprimento-dos-contratos > . Acesso em: 10 de ago. 2013.

Rioja, F. (2003). The penalities of inefficiency in infraestructure. Review of Development Economics. $7(1)$.

Spence, M. (1973). Job Market Signaling. The Quarterly Journal of Economics. 87(3) 355-374.

Tullock, G. (1967). The Welfare Costs of Tarrifs, Monopolies and Theft. Western Economic Journal. 